\title{
Identification of potential prognostic biomarkers for node-negative breast tumours by proteomic analysis: A multicentric 2004 national PHRC study
}

\author{
FRANÇOISE DESCOTES ${ }^{1}$, PASCAL JÉZÉQUEL ${ }^{2}$, FRÉDÉRIQUE SPYRATOS ${ }^{3}$, LOÏC CAMPION ${ }^{4}$, \\ CATHERINE GRENOT ${ }^{1}$, FLORENCE LEREBOURS ${ }^{5}$, MARIO CAMPONE ${ }^{6}$, \\ CATHERINE GUÉRIN-CHARBONNEL ${ }^{4}$, DIDIER LANOË ${ }^{2}$, MARJORIE ADAMS ${ }^{1}$, \\ JEAN ANDRÉ ${ }^{1}$, ANTOINE CARLIOZ ${ }^{7}$, PIERRE-MARIE MARTIN ${ }^{7}$, \\ AGNÈS CHASSEVENT $^{8}$, MARIE-LISE JOURDAN ${ }^{9}$, CATHERINE GUETTE ${ }^{8}$, \\ ISABELLE ZANELLA-CLEON $^{10}$ and GABRIEL RICOLLEAU ${ }^{2}$
}

\begin{abstract}
${ }^{1}$ Department of Biochemistry Molecular Biology, Hospices Civils de Lyon (HCL), CHU Lyon Sud,
F-69495 Pierre Bénite Cedex; ${ }^{2}$ Department of Oncology Biology, René Gauducheau Cancer Center,

F-44805 Nantes - Saint Herblain Cedex; ${ }^{3}$ Department of Oncogenetics, Institut Curie - Hôpital René Huguenin,

F-92210 St-Cloud; ${ }^{4}$ Biostatistics Unit, René Gauducheau Cancer Center, F-44805 Nantes - Saint Herblain Cedex;

${ }^{5}$ Department of Medical Oncology, Institut Curie - Hôpital René Huguenin, F-92210 St-Cloud; ${ }^{6}$ Department of

Medical Oncology, René Gauducheau Cancer Center, F-44805 Nantes - Saint Herblain Cedex; ${ }^{7}$ Transfer Laboratory of

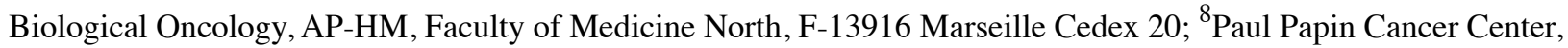

F-49933 Angers Cedex 9; ${ }^{9}$ Laboratory of Oncology, CORAD, CHU Bretonneau, F-37044 Tours Cedex;

${ }^{10}$ Center for Microanalysis of Proteins, UMS3444 Lyon-Gerland Sud BioSciences, Institute of Biology and Chemistry of Proteins, F-69007 Lyon, France
\end{abstract}

Received December 22, 2011; Accepted February 20, 2012

DOI: 10.3892/ijo.2012.1456

\begin{abstract}
We used a 2D-electrophoresis (2-DE) proteomic approach to identify novel biomarkers in node-negative breast cancers. This retrospective study focused on a population of patients with ductal pNOM0 tumours. A subset of patients who developed metastases and in whose tumours were found high levels of uPA and PAI-1 (metastatic relapse, MR: $n=20$ ) were compared to another subset in whom no metastatic relapse occurred and whose tumours were found to have low levels of UPA and PAI-1 (no relapse, NR: $n=21$ ). We used a 2-DE coupled with MS approach to screen cytosol fractions using two $\mathrm{pH}$-gradient scales, a broad scale (3.0-11.0) and a narrower scale focussing in on a protein rich region (5.0-8.0). This study was conducted on 41 cytosol specimens analyzed in duplicate on two platforms. The differential analysis of more than 2,000 spots in 2-DE gels, obtained on the two platforms, allowed the identification of 13 proteins which were confirmed by western
\end{abstract}

Correspondence to: Dr Françoise Descotes, Department of Biochemistry Molecular Biology, Pavillon 3D, Hospices Civils de Lyon (HCL), CHU Lyon Sud, F-69495 Pierre Bénite Cedex, France

E-mail: francoise.descotes@chu-lyon.fr

Key words: breast cancer, proteomic, 2D electrophoresis, node negative, prognosis, biomarkers blotting. Two proteins, GPDA and FABP4 were down-regulated in the MR subset whereas all the others were up-regulated. An in silico analysis revealed that GMPS (GUAA), GAPDH (G3P), CFL1 (COF1) and FTL (FRIL), the most informative genes, displayed a proliferation profile (high expression in basal-like, $\mathrm{HER}^{+}$and luminal B molecular subtypes). Inversely, similar to FABP4, GPD1 [GPDA] displayed a high expression in luminal A subtype, a profile characteristic of tumour suppressor genes. Despite the small size of our cohort, the 2-DE analysis gave interesting results which were confirmed by the in silico analysis showing that some of the corresponding genes had a strong prognostic impact in breast cancer, mostly because of their link with proliferation: GMPS, GAPDH, FTL and GPD1. A validation phase on a larger cohort is now needed before these biomarkers could be considered for use in clinical practice.

\section{Introduction}

Patients diagnosed with sporadic breast cancer have been shown to have markedly different clinical outcome and underlining the need for further molecular characterization of this disease to allow improved patient monitoring. Approximately $70 \%$ of patients with node-negative breast cancer will be metastasis-free 10 years after initial treatment without adjuvant chemotherapy, while $30 \%$ will develop metastatic relapse (MR). Traditional prognostic markers (age at diagnosis, tumour size, hormonal 
receptor status, tumour grade) are not sufficient for precise riskgroup discrimination in breast cancer (1). Current guidelines, such as those of St Gallen or NIH, recommend adjuvant systemic chemotherapy for more than $90 \%$ of node-negative breast cancer patients, which results in over-treatment and increases morbidity and treatment costs (2-5). Converging data have shown the importance of the two components of the plasminogen activator system, uPA and PAI-1, in predicting the risk of metastasis of node-negative breast cancer $(6,7)$. However, despite their power, uPA and PAI-1 are not $100 \%$ reliable at predicting metastatic risk. Therefore research in node-negative breast cancer now focuses on identifying more powerful prognostic markers to help direct treatment decisions by subtyping of patients into risk subgroups who may or may not benefit from adjuvant therapy. The era of large-scale science linked both to recent technological advances and to the availability of complete genetic information, has boosted the search for new biomarkers. Today, techniques involving high-throughput screening of molecular compartments such as the genome, the transcriptome and the proteome can be accessed by many research groups. Proteome analysis is currently accomplished by a combination of two-dimensional gel electrophoresis (2-DE) to separate and visualize proteins and mass spectrometry (MS) or tandem MS (MS/MS) to identify the selected protein spots. Important technical advances regarding 2-DE and protein MS have increased the sensitivity, reproducibility and throughput of proteome analysis while creating an integrated technology. While much effort has been devoted to screening the breast cancer tumour transcriptome to identify prognostic markers, the breast cancer tumour proteome has been less investigated (8-12). To our knowledge, aside one of our works based on SELDI-TOF-MS profiling, no other study using high throughput proteomic approaches has focused on node-negative breast cancer tumours to identify prognostic biomarkers (13).

In the present study, we used a 2-DE coupled with MS approach to screen the cytosol fraction of node-negative breast cancers. We focused on a population of patients with ductal pNOM0 tumours showing clinically homogeneous behaviour but which were biologically heterogeneous potentially leading to their opposing outcomes. We compared patients with extreme levels of uPA and PAI-1 associated with opposite outcomes to identify robustly differentially expressed proteins: patients with tumours containing high levels of UPA and PAI-1 and who developed metastases (MR) were compared to those with tumours containing low levels of UPA and PAI-1 and who did not suffer metastatic relapse (NR). These very restrictive selection criteria associated with at least 10 -years follow-up required the recruitment of patients from 4 medical centres.

This study was performed on two proteomic platforms with experience using 2-DE situated in Nantes and Lyon and was conducted blind using two complementary methodological approaches to optimize results.

\section{Materials and methods}

Patient selection and tumour characteristics. This study retrospectively included 41 selected women with sporadic node-negative primary breast tumours, diagnosed and treated in 4 medical centres (Institut Curie - René Huguenin Hospital, St Cloud; Centre René Gauducheau, St Herblain; Centre Hospitalier Lyon sud; AP-HM, Marseille), between 1981 and 1998. Median age at diagnosis was 54 years (range 36-76). Informed consent was obtained from patients to use their surgical specimens and clinicopathological data for research purposes, as required by the French Committee for the Protection of Human Subjects. All patients had an infiltrating ductal carcinoma and showed no evidence of distant metastasis at the time of diagnosis. None had received chemotherapy, endocrine therapy or radiation therapy prior to surgery. Treatment decisions were based solely on consensus recommendations at the time of diagnosis. Patients were followed-up for MR (nodal or distant metastasis; local relapses were excluded). For the study we selected from a population of patients with invasive ductal node-negative tumours without adjuvant chemotherapy, two groups as different as possible both from an evolutionary and a biological perspective to identify differentially expressed proteins. Twenty patients (MR subset) with metastatic relapse and whose tumours had high levels of uPA and PAI-1 (median time to metastasis 2.6 years; range 0.48-8.39) were compared with 21 patients (NR subset) without metastatic relapse and whose tumours had low levels of uPA and PAI-1. For this second group, the median followup was 15.25 years (range 11.26-21.99). The clinicopathologic characteristics of the patients are indicated in Table I.

Cytosol preparation. The cytosolic fractions used in this study were initially prepared for hormone receptor assays at the time of surgery in the four centres of sample collection using the same protocol by homogenizing fragments in the following buffer: $10 \mathrm{mM}$ Tris- $\mathrm{HCl}, \mathrm{pH} 7.4,1.5 \mathrm{mM}$ EDTA, 10 $\mathrm{mM}$ sodium molybdate, $0.5 \mathrm{mM}$ dithiotreitol, $10 \%$ glycerol. Homogenates were centrifuged at 105,000 $\mathrm{g}$ for $1 \mathrm{~h}$ and supernatants were aliquoted and thereafter stored in liquid nitrogen until use. For this study, protein concentrations were remeasured retrospectively in one laboratory using the Bradford method (14).

Selection of the two studied subsets. Each of the four centres measured UPA and PAI-1 in their samples by the enzymelinked immunoassay (uPA: Imubind no. 894; PAI-1, Imubind no. 821, American Diagnostica) using the method developed within their respective laboratory $(15,16)$. In each laboratory, cytosols were classified into 4 quartile groups based on levels of UPA and PAI-1. From cytosols with low UPA and PAI-1 (1st quartile) and high uPA and PAI-1 (4th quartile), two subsets of samples were retained: respectively $21 \mathrm{NR}$ and $20 \mathrm{MR}$ as defined in 'Patient selection and tumour characteristics'.

\section{Two-dimensional gel electrophoresis}

Team Nantes. For the first dimension, 24-cm Immobiline DryStrips [ReadyStrips IPG Strips 24 cm, pH 3.0-11.0 nonlinear(NL) (analytical gels and preparative gels), GEHealthcare, Aulnay sous Bois, France] were passively rehydrated overnight with $450 \mu 1$ Destreak buffer (GE Healthcare) and isoelectric focusing (IEF) was performed using a PROTEAN IEF Cell electrophoresis system (Bio-Rad, Hercules, CA) at $19^{\circ} \mathrm{C}$. Samples containing a mix of IEF markers (Bio-Rad) and either $30 \mu \mathrm{g}$ of cytosolic proteins for analytical gels or $200 \mu \mathrm{g}$ for preparative gels were diluted in a buffer composed of 7 M urea, 2 M thiourea, 4\% w/v CHAPS, $0.4 \%$ Triton X-100, $0.5 \%$ IPG buffer pH 3.0-11.0 NL (GE Healthcare), $0.28 \%$ DTT, 
Table I. Clinicopathologic characteristics of the 41 studied patients.

\begin{tabular}{cccc}
\hline Characteristics & $\begin{array}{c}\text { No metastatic } \\
\text { relapse } \\
\text { subset }\end{array}$ & $\begin{array}{c}\text { Metastatic } \\
\text { relapse } \\
\text { subset }\end{array}$ & p-value \\
\hline
\end{tabular}

n

21

20

Median age

$54(37-71)$

$55(36-76)$

0.548

at diagnosis (years)

Tumour size

$15(10-67)$

25 (15-40)

0.002

(mean, mm)

Tumour size (mm)

$\begin{array}{crr}\mathrm{pT}<20 & 14 & 6 \\ \mathrm{pT} \geq 20 & 7 & 14\end{array}$

SBR grade ${ }^{a}$

I

4

3

9

III

14

3

8

Estrogen receptor

receptor status

Positive

Negative

6

14

Progesterone

receptor status

Positive

10

10

Negative

11

10

Adjuvant therapy

Radiotherapy

Hormonotherapy

$\begin{array}{ccc}18 & 11 & 0.043 \\ 1 & 2 & 0.606 \\ 3.3(2.2-4.5) & 3.5(2.4-4.8) & 0.017\end{array}$

NPI grade

$\begin{array}{lccc}1 & 14 & 8 & 0.121 \\ 2 & 7 & 12 & \\ 3 & 0 & 0 & \\ & & & \\ \text { AOL }^{c} \text { 10-year- } & 25(15-50) & 37(25-47) & 0.010 \\ \text { relapse risk } & & & \end{array}$

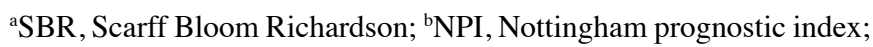
${ }^{\mathrm{c}} \mathrm{AOL}$, Adjuvant! Online.

and traces of Orange $\mathrm{G}$ dye to obtain a final volume of $80 \mu 1$ before being cuploaded on strips. The linear ramping mode of the IEF voltage for analytical and preparative gels was applied according to the following parameters: $250 \mathrm{~V}$ for $1 \mathrm{~h}$ and $10,000 \mathrm{~V}$ for $1 \mathrm{~h}$ with rapid ramping until a total of 160,000
Vh was reached. Following IEF, the strips were collected in a plastic bag and frozen at $-80^{\circ} \mathrm{C}$ until use.

For the second dimension, the strips were first equilibrated at room temperature for $15 \mathrm{~min}$ in $10 \mathrm{ml}$ of $50 \mathrm{mM}$ Tris- $\mathrm{HCl}$ $\mathrm{pH} 8.8$ buffer containing $6 \mathrm{M}$ urea, $2 \%$ SDS, $30 \%$ glycerol and $65 \mathrm{mM}$ DTT (reduction step) and then transferred to $10 \mathrm{ml}$ of $50 \mathrm{mM}$ Tris- $\mathrm{HCl} \mathrm{pH} 8.8$ buffer containing $6 \mathrm{M}$ urea, 2\% SDS, $30 \%$ glycerol and $135 \mathrm{mM}$ iodoacetamide for $20 \mathrm{~min}$ (alkylation step). The strips were washed with electrophoresis buffer (25 mM Tris- $\mathrm{HCl} \mathrm{pH} \mathrm{8.3,} 192 \mathrm{mM}$ glycine, 0.1\% SDS), fixed with $0.5 \%$ agarose on top of a $24 \times 20-\mathrm{cm}$ polyacrylamide gradient gel (9-18\%) and run on an Ettan ${ }^{\mathrm{TM}}$ DALTsix electrophoresis system (GE Healthcare) according to the manufacturer's recommendations. The electrophoresis was performed at $40 \mathrm{~V}$ for $1 \mathrm{~h}$ then at $300 \mathrm{~V}$ for $16 \mathrm{~h}\left(50 \mathrm{~mA}\right.$ maximum) at $10^{\circ} \mathrm{C}$, and was stopped when the LMW marker orange G dye (Sigma-Aldrich, SaintQuentin Fallavier, France) used as a reference had disappeared. Each sample was treated in at least two independent 2-DE replicates.

Team Lyon. For the first dimension, samples containing a mixture of ampholytes and either $30 \mu \mathrm{g}$ of cytosolic proteins for analytical gels or $200 \mu \mathrm{g}$ for preparative gels were mixed in a rehydration buffer composed of $7 \mathrm{M}$ urea, $2.3 \mathrm{M}$ thiourea, 4\% w/v CHAPS, $0.24 \%$ Triton X-100, $1 \mathrm{X}$ Biolyte 3/10 ampholyte (Bio-Rad), $20 \mathrm{mM}$ DTE, and traces of bromophenol blue to obtain a final volume of $350 \mu 1$. IPG strips [17 cm pH 5.0-8.0 (Bio-Rad)] were passively rehydrated. IEF was performed using the PROTEAN IEF Cell electrophoresis system (Bio-Rad). The linear ramping mode of the IEF voltage for analytical and preparative gels was applied according to the following parameters: $50 \mathrm{~V}$ for $1 \mathrm{~h}, 200 \mathrm{~V}$ for $1 \mathrm{~h}, 1000 \mathrm{~V}$ for $1 \mathrm{~h}$ and $10,000 \mathrm{~V}$ during $2 \mathrm{~h}$ until a total of $40,000 \mathrm{Vh}$ was obtained, before a final step of $500 \mathrm{~V}$ for $18 \mathrm{~h}$. After IEF, the strips were collected and frozen at $-80^{\circ} \mathrm{C}$ until use.

For the second dimension, the strips were first equilibrated at room temperature for $10 \mathrm{~min}$ in $6 \mathrm{ml}$ of $375 \mathrm{mM}$ Tris- $\mathrm{HCl}$ pH 8.8 buffer containing $6 \mathrm{M}$ urea, $2 \%$ SDS, $20 \%$ glycerol and $133 \mathrm{mM}$ DTE (reduction step) before being transferred to $6 \mathrm{ml}$ of $375 \mathrm{mM}$ Tris- $\mathrm{HCl} \mathrm{pH} 8.8$ buffer containing $6 \mathrm{M}$ urea, 2\% SDS, $20 \%$ glycerol and $135 \mathrm{mM}$ iodoacetic acid for $10 \mathrm{~min}$ (alkylation step). The strips were then washed with electrophoresis buffer (25 mM Tris- $\mathrm{HCl} \mathrm{pH} 8.3,192 \mathrm{mM}$ glycine, $5 \mathrm{mM}$ sodium thiosulfate, $0.2 \%$ SDS), fixed with $0.5 \%$ agarose on top of a 19x20 cm polyacrylamide gradient gel (9-18\%) and run on a Protean II Xi Multi Cell electrophoresis system (Bio-Rad) according to the manufacturer's recommendations. The electrophoresis was performed at $50 \mathrm{~V}$ for $1 \mathrm{~h}$ and at $250 \mathrm{~V}$ for $16 \mathrm{~h}$ (35 mA/gel) at $8^{\circ} \mathrm{C}$. For each sample, 2-DE was repeated at least twice in independent replicates.

Detection of proteins by silver staining. In both laboratories, analytical gels were silver-stained (17). For preparative gels, the silver-staining protocol was performed as described by O'Connell and Stults (18). When necessary, the preparative gels were stored in $1 \%$ acetic acid at $4^{\circ} \mathrm{C}$ for no more than 30 days, until the excision of protein spots.

\section{Image analysis}

Team Nantes. The stained gels were digitized using a densitometer (ImageScanner, Bio-Rad) and analyzed with the Melanie 3 
computer software (GeneBio, Geneva, Switzerland). Spot detection, quantification and matching were performed with Melanie 3 tools. After choosing manually 420 common spots as landmarks, the alignment and matching was performed. Spot intensities given as spot volumes were normalized to the total spot volume. A master gel was prepared by the combination of two sub-master gels, MR-pool and NR-pool. On one side, $1.5 \mu \mathrm{g}$ of each of the $20 \mathrm{MR}$ samples were mixed to obtain the MR-pool and on the other the 21 NR samples for the NR-pool. The master gel was then constructed by numerical combination of the two sub-master gels.

Team Lyon. The stained gels were digitized using a densitometer (ImageScanner, GE Healthcare) and analyzed with the Progenesis SameSpots version v3.2 (Nonlinear Dynamics, Newcastle upon Tyne, UK). Before spot detection, all the images were aligned (100\% matching) to a reference image. From 2,015 aligned spots in all images, the statistical analysis performed with the Progenesis SameSpots software with three criteria: fold $>1.5$, p-Anova $<0.05$ and power $>0.8$, permitted the selection of spots differentially expressed between the 2 subsets.

\section{Statistical analysis}

Discriminating spots identification. The first aim was to identify robust spots displaying statistically significant differences in intensity according to patient outcome. For each patient, the 2,404 Nantes and the 2,015 Lyon relative spot intensity values were extracted twice and the two replicates with the highest correlation coefficient were kept ( $r>0.80)$. Both individual values and the mean of the two values were then used for statistical analysis. In order to strengthen the accuracy of the spots selection in this small population, it was necessary to use methods with repeated permutations. The local false discovery rate (FDR) and q-value of each spot were calculated by means of SAM software distributed by Stanford University (19). The FDR and permutation p-values of each spot were also calculated by means of BRB-Arrays 3.8.1 developed by Dr Richard Simon and BRB-ArrayTools Development Team.

List of discriminating spots. Spots in the Nantes and Lyon datasets showing significance (based on FDRs $<10^{-3}$ and/or permutation $\mathrm{p}$ - or q-value $<10^{-3}$ ) with both statistical tools in both series and in the averaged series were selected for further analyses. Nantes and Lyon selected spots were pooled. Then, a top-14 spots was determined based on best FDR scores.

\section{Biomarker identification and database search}

Team Nantes. Spots were recovered using the Ettan Spot picker (GE Healthcare) and individually treated with the Proteoextract All-in-one Trypsin Digestion kit (Calbiochem, Merck Chemicals Ltd., Nottingham, UK) according to the manufacturer's instructions. Peptide digests were concentrated on C18-Zip Tips (Millipore, Billerica, MA, USA) and eluted with $1.5 \mu \mathrm{l} \alpha$-cyano4-hydroxycinnamic acid matrix solution (in 50\% acetonitrile, $0.05 \%$ trifluoroacetic acid) onto a MALDI-TOF target plate (Opti-TOF 384 well insert, AB Sciex, France). Peptide spectra acquisition was realized on the $4800 \mathrm{MALDI}$ TOF/TOF analyzer (AB Sciex). After screening the sample position in MS-positive reflector mode using 1500 laser shots, the fragmentation of automatically-selected precursors was performed with $1 \mathrm{kV}$ collision energy using air as the collision gas (pressure of $2 \times 10^{-6}$ Torr). MS spectra were acquired between $\mathrm{m} / \mathrm{z} 800$ and 4000. Up to 12 of the most intense ion signals having an $\mathrm{S} / \mathrm{N}>12$ were selected as precursors for MS/MS acquisition. Peaklist generation and protein identification were performed by the ProteinPilot ${ }^{\mathrm{TM}}$ Software V 2.0 (AB Sciex) using the Paragon algorithm. Each MS/MS spectrum was searched across all species and then against the Homo Sapiens (Swissprot-Uniprot) selected database. The searches were run with the fixed modification of iodoacetamide-labelled cysteine parameters. Other parameters such as tryptic cleavage specificity, precursor ion mass accuracy and fragment ion mass accuracy are MALDI 4800 built-in functions of ProteinPilot software. The preliminary protein identifications obtained automatically from the software were inspected manually for conformation prior to acceptance.

\section{Team Lyon}

In-gel digestion. Silver-stained protein spots were excised from the preparative gels and destained according to the method of Gharahdaghi et al (20). Proteolytic digestion was done in-gel using 5-10 $\mu \mathrm{l}$ of a trypsin solution $\left(10 \mathrm{ng} / \mu \mathrm{l}\right.$ in $50 \mathrm{mM} \mathrm{NH}_{4} \mathrm{HCO}_{3}$; sequence-grade trypsin, Promega, France) for $45 \mathrm{~min}$ at $50^{\circ} \mathrm{C}$. The resulting tryptic peptides from the supernatant fraction were recovered. A second extraction step was performed using $10-15 \mu \mathrm{l}$ of $\mathrm{H}_{2} \mathrm{O} / \mathrm{CH}_{3} \mathrm{CN} / \mathrm{HCOOH}(60 / 36 / 4$; v/v/v) for $30 \mathrm{~min}$ at $30^{\circ} \mathrm{C}$. Finally, all extracts were pooled and dried in a vacuum concentrator and then resuspended in $0.3 \%$ trifluoroacetic acid $(12 \mu \mathrm{l})$ for LC-MS/MS analyses.

NanoLC/nanospray/tandem mass spectrometry (LC-ESI/MS/ $M S)$. Experiments were performed on a Q-STAR XL instrument (AB Sciex). The information dependent acquisition (IDA) mode allowed peptide ions within a m/z 400-1600 survey scan mass range to be analyzed for subsequent fragmentation. MS/MS spectra were acquired in the $\mathrm{m} / \mathrm{z}$ 65-2000 range for the +2 to +4 charged ions. The collision energy was automatically set by the software (Analyst 1.1, AB Sciex) and was related to the mass and the charge of the precursor ion. Tryptic peptides were separated using an Ultimate-nanoLC (Dionex, France) with a C18 PepMap micro-precolumn (5 $\mu \mathrm{m} ; 100 \AA$; $300 \mu \mathrm{m}$ x 5 mm; Dionex) and a C18 PepMap nanocolumn (3 $\mu \mathrm{m} ; 100 \AA ̊ ⒎ 75 \mathrm{~m} \mathrm{x} 150 \mathrm{~mm}$; Dionex). The chromatographic separation was developed using a linear 30 min gradient from 0 to $60 \% \mathrm{~B}$, where solvent $\mathrm{A}$ was $0.1 \% \mathrm{HCOOH}$ in $\mathrm{H}_{2} \mathrm{O} / \mathrm{CH}_{3} \mathrm{CN}(95 / 5)$ and solvent $\mathrm{B}$ was $0.1 \%$ $\mathrm{HCOOH}$ in $\mathrm{H}_{2} \mathrm{O} / \mathrm{CH}_{3} \mathrm{CN}(20 / 80)$ at $300 \mathrm{nl} / \mathrm{min}$ flow rate. Protein identification was achieved by the Paragon Algorithm from the ProteinPilot software (AB Sciex) against the SwissProt database limited to the human species.

Western blotting. Cytosolic proteins $(20 \mu \mathrm{g})$ were electrophoresed on a $12.5 \%$ polyacrylamide gel at $400 \mathrm{~V}$ for $2 \mathrm{~h}$ according to the standard protocol (21). The proteins were then transferred to nitrocellulose for $7 \mathrm{~min}$ at $20 \mathrm{~V}$ using an iBlot Dry Blotting System (Invitrogen, Carlsbad, CA) according to the manufacturer's protocol. After an overnight incubation at $4^{\circ} \mathrm{C}$ in a blocking buffer (25 mM Tris-HCl, pH 7.4, $150 \mathrm{mM} \mathrm{NaCl,} \mathrm{0.05 \%} \mathrm{Tween-20)}$ containing $5 \%$ non-fat dry milk, the membranes were incubated for $2 \mathrm{~h}$ at room temperature in the above buffer containing $1 \%$ non-fat dry milk and one of the primary antibodies at an appropriate dilution (Table II). After washing for $30 \mathrm{~min}$ with 
Table II. Western blotting conditions.

\begin{tabular}{llll}
\hline Protein & \multicolumn{1}{c}{ Reference } & Dilution & Host \\
\hline ARPC3 & PAB6621, Abnova, Taipei, Taiwan & $1: 80$ & Goat \\
COF1 & PAB5302, Abnova & $1: 400$ & Rabbit \\
IF5A1 & NB600-1077, Novus Biologicals, Litlleton, CO, USA & $1: 1000$ & Rabbit \\
FABP4 & H00002167-A01, Abnova & $1: 1000$ & Mouse \\
FRIL & FERL14A, Alpha Diagnostic, San Antonio, TX, USA & $1: 125$ & Rabbit \\
FUBP1 & H00008880-A01, Abnova & $1: 500$ & Mouse \\
G3P & H00002597-A01, Abnova & $1: 1500$ & Mouse \\
GUAA & H00008833-A01, Abnova & $1: 250$ & Mouse \\
GPDA & H00002819-A01, Abnova & $1: 1000$ & Mouse \\
NNMT & H00004837-A01, Abnova & $1: 250$ & Mouse \\
PPIB & SP5113P, Acris Antibodies GmbH, Herford, Germany & $1: 333$ & Rabbit \\
SNX6 & AP1464A, Abgent, San Diego CA, USA & $1: 50$ & Rabbit \\
TAGL & sc-53932, Santa Cruz Biotechnology, Santa Cruz, CA, USA & $1: 200$ & Mouse \\
\hline
\end{tabular}

blocking buffer without milk, the membranes were incubated first for 90 min with anti-mouse $\operatorname{IgG}$ (1:4000, no. E0354, Dako, Glostrup, Denmark), anti-rabbit IgG (1:4000, no. E0432, Dako) or anti-goat IgG (1:4000, no. E0466, Dako) biotinylated secondary antibodies, and for $1 \mathrm{~h}$ with streptavidin biotinylated horseradish peroxydase (HRP) conjugate (GE Healthcare). The chemiluminescent signals were visualized using the SuperSignal West Pico chemiluminescent substrate (Thermo Fisher Scientific, Lafayette, $\mathrm{CO}$ ) according to the manufacturer's protocol and the light emission was captured with the LAS 4000 camera (Fujifilm Medical Ltd., Tokyo, Japan) and signal intensity was analysed by the Multi Gauge software v3.0 (Fujifilm). The membrane was reprobed with anti- $\beta$-actin (1:50000, no. A5541, Sigma-Aldrich) for loading control.

In silico analysis. Prognostic informativity of these protein biomarkers was explored at the RNA level by means of bc-GenExMiner v2.0 web tool (22). Briefly, this user-friendly, web-based application based on breast cancer DNA microarray results permits the evaluation of gene prognostic informativity by means of targeted and exhaustive analysis. The prognostic impact of genes is evaluated by means of a Cox proportional hazards model. A targeted analysis performs gene-based survival analyses for each cohort separately and all cohorts pooled together (Table III); cohorts may be split by $\mathrm{N}$ and estrogen receptor (ER) status and analyses may be based on 5 different event criteria. In an exhaustive analysis, the prognostic informativity is evaluated for each of the possible pools corresponding to every combination of population ( $\mathrm{N}$ and ER status) and event criteria. Furthermore, bc-GenExMiner provides gene expression maps according to molecular subtypes.

\section{Results}

The same 41 breast cancer cytosols (21 NR and $20 \mathrm{MR}$ ) were analyzed by 2 -DE analysis using complementary methodological approaches, using a broad $\mathrm{pH}$ range $(3.0-11.0)$ in the first dimension and a narrower $\mathrm{pH}$ range (5.0-8.0) focusing in on a protein-rich region. All cytosols were screened twice in two independent tests and the gels were independently analyzed with Melanie or Progenesis SameSpots Software. The two sets of 2-DE gels obtained using the broad range (NL pH 3.0-11.0, Nantes) and the narrower range ( $\mathrm{pH}$ 5.0-8.0, Lyon) presented 2,404 spots and 2,015 spots respectively. Representative 2-DEgels obtained in the 2 site conditions are displayed in Fig. 1.

Statistical analysis and protein identification. The spots of two series of 2-DE gels were compared with robust permutation techniques (based on FDRs $<10^{-3}$ and/or 10,000 permutation p- or q-value $<10^{-3}$ ) permitting the selection of 65 and 26 spots, for Lyon and Nantes, respectively (Fig. 1). Among the 91 spots, 14 spots were finally retained based on FDR best scores: 9 spots from $\mathrm{pH}$ 5.0-8.0 and 5.0 from $\mathrm{pH}$ 3.0-11.0 (Table IV) and their identity revealed using mass spectrometry and database search. Among these proteins, transgelin (TAGL) was found by both teams. Other proteins were: nicotinamide N-methyltransferase (NNMT), glutamine amidotransferase (GUAA), ferritin light chain (FRIL), actin related protein $2 / 3$ complex, subunit 3 (ARPC3), glyceraldehyde-3-phosphate dehydrogenase (G3P), peptidyl-prolyl cis-trans isomerase B (PPIB), far upstream element-binding protein 1 (FUBP1), glycerol-3-phosphate dehydrogenase (GPDA), eukaryotic translation initiation factor 5A-1 (IF5A1), fatty acid-binding protein, adipocyte type (FAPB4), sorting nexin-6 (SNX6) and cofilin 1 (COF1) (Table V).

Western blotting. The differential expression of these proteins between the NR and MR subgroups tested in 2-DE, was validated by western blot analysis (Fig 2 and Table VI). As shown by $2-\mathrm{DE}$ analysis most of the identified proteins $(n=11)$ were overexpressed in the MR group. By contrast, FABP4 and GPDA were overexpressed in the NR group.

\section{In silico analysis}

Targeted analysis. Expression results at the RNA level with MR as the event were concordant with 2-DE ones concerning expression in node-negative breast cancer patients for GMPS 


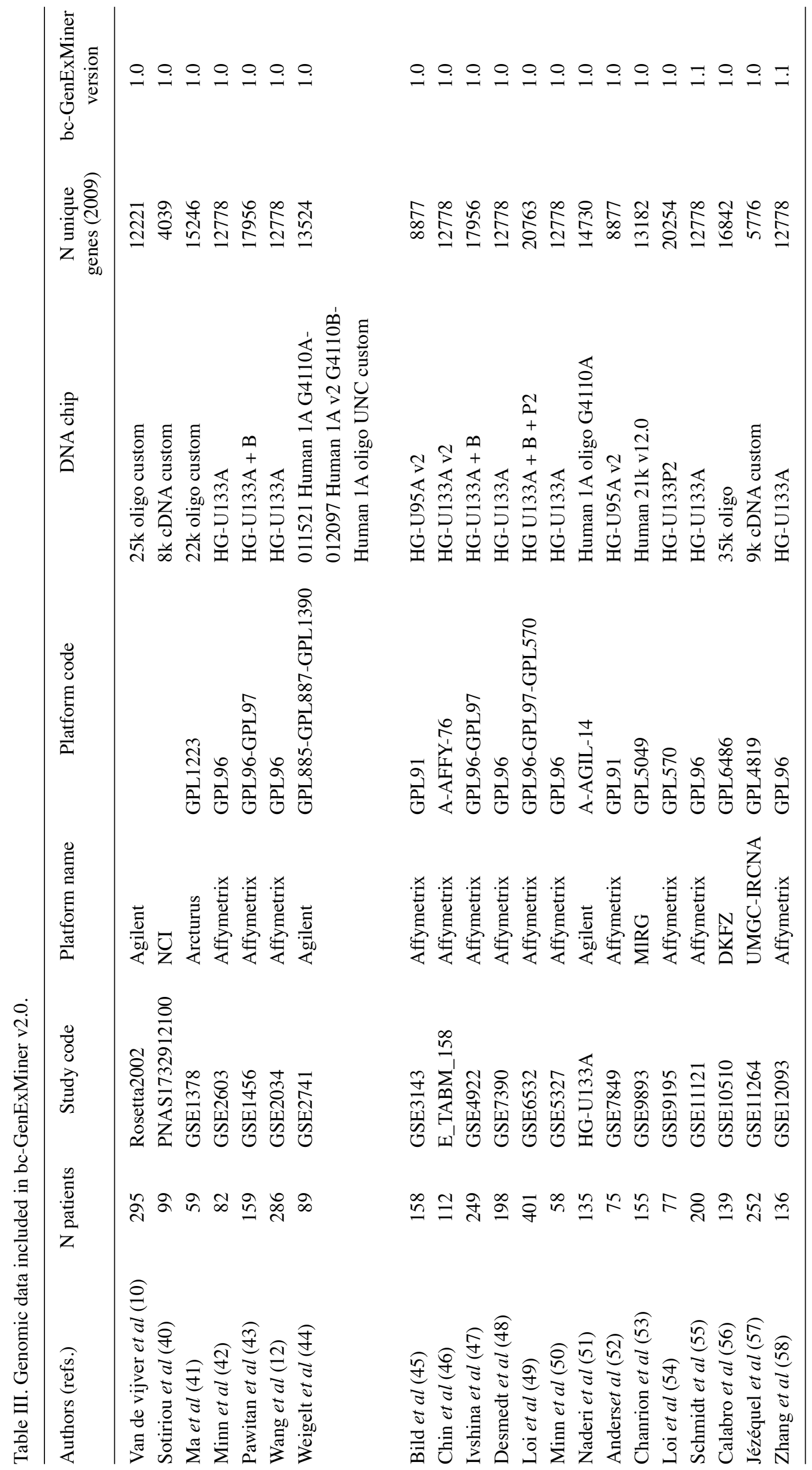


A

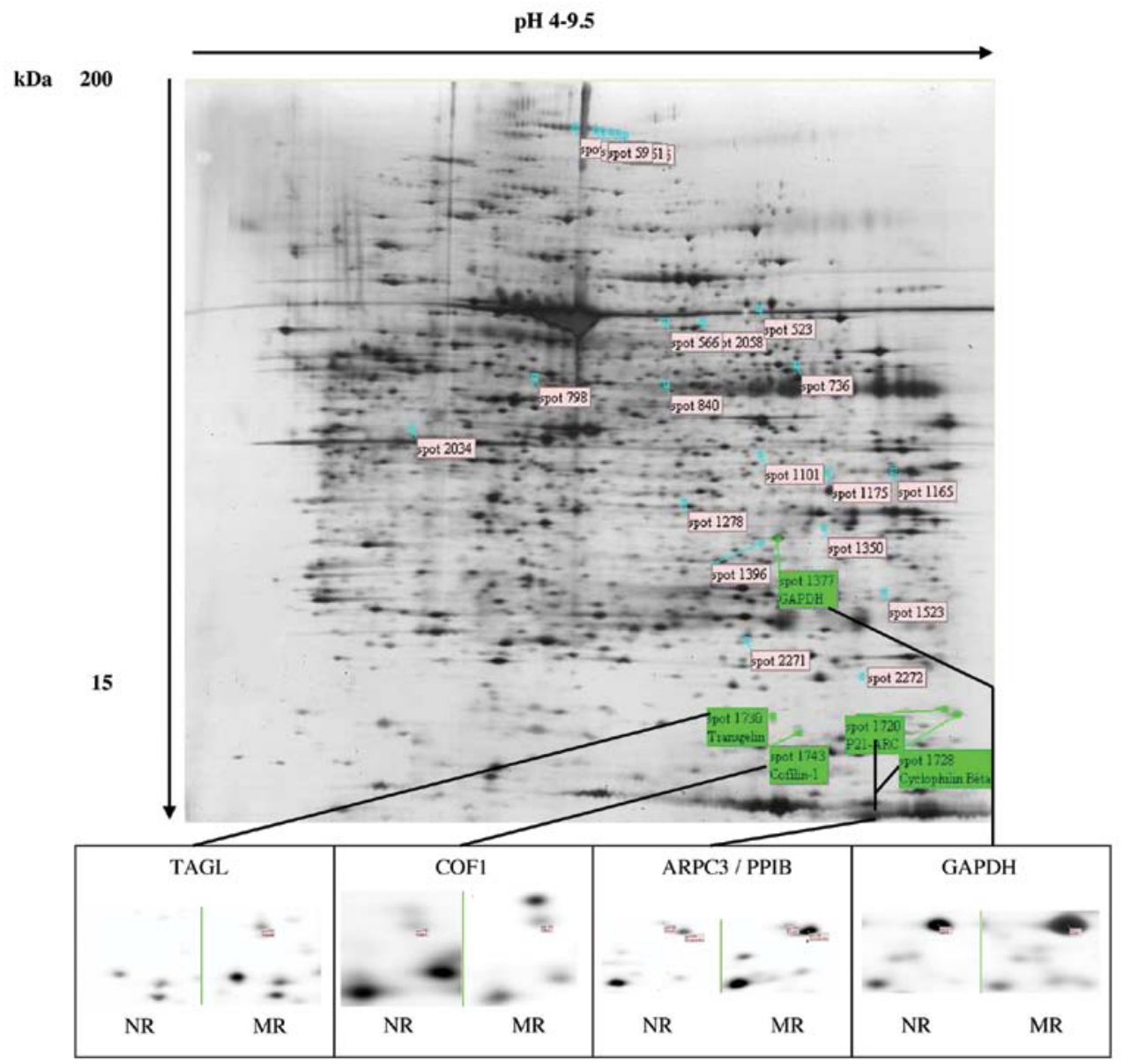

B

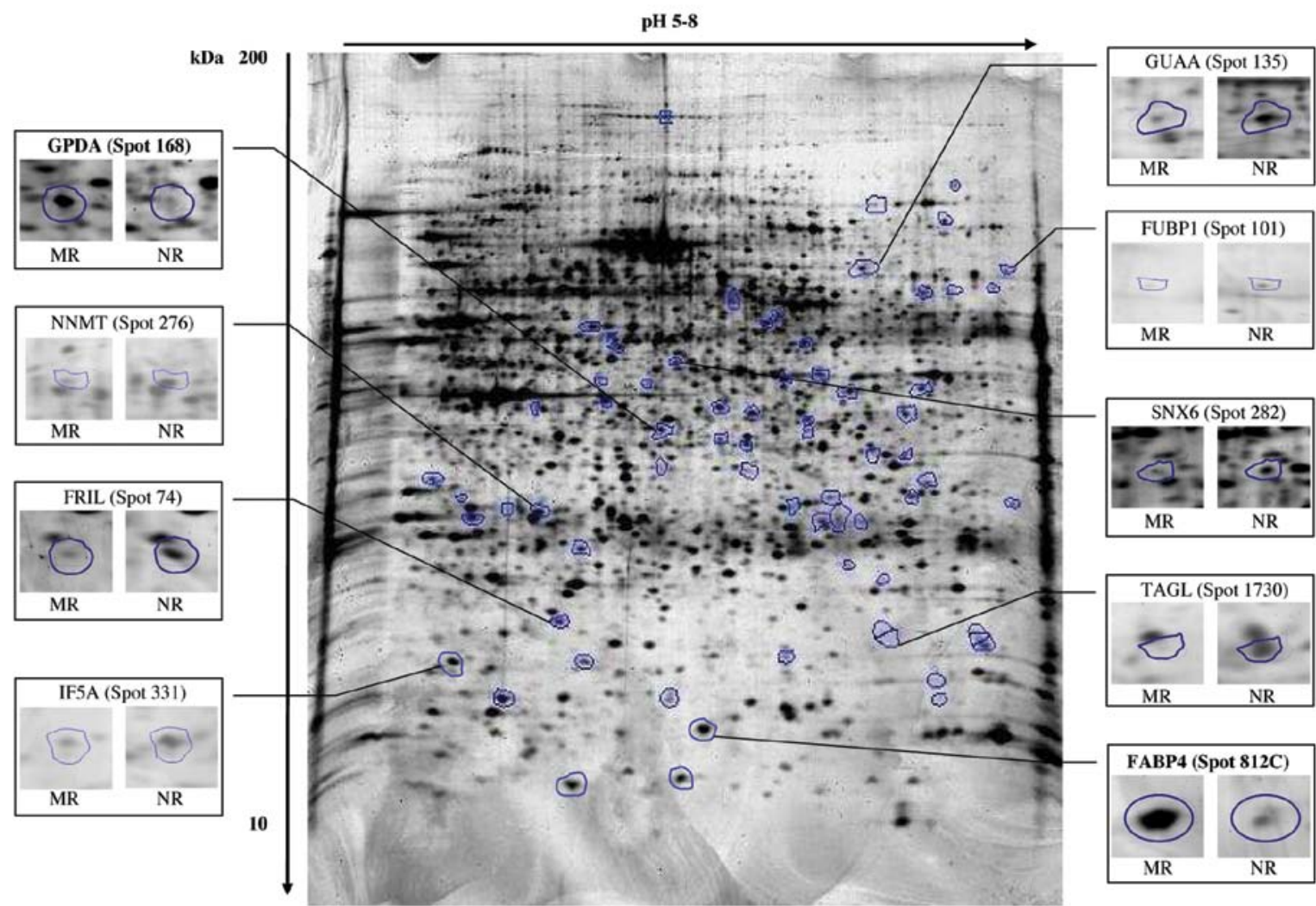

Figure 1. Typical 2-DE gels. Representative 2-DE pattern [non-linear $\mathrm{pH}$ 3.0-11.0 (A) or pH 5.0-8.0 (B) in the first dimension and 9-18\% SDS-PAGE in the second] of cytosol protein content from a node-negative breast tumour. Proteins are silver-stained. Discriminating protein spots submitted to MS identification are displayed with a numbered tag. MR, metastatic relapse; NR, no metastatic relapse as defined in Materials and methods. 
Table IV. Identification of top-13 selected proteins: statistical classification based on FDR best scores and protein characteristics.

\begin{tabular}{|c|c|c|c|c|c|c|c|c|c|}
\hline \multirow[b]{3}{*}{ Class } & \multicolumn{4}{|c|}{ Statistical analysis } & \multirow[b]{3}{*}{ Protein } & \multirow[b]{3}{*}{ Spot no. } & \multirow[b]{3}{*}{$\mathrm{pI}$} & \multirow[b]{3}{*}{ MW } & \multirow[b]{3}{*}{ Team } \\
\hline & \multicolumn{2}{|c|}{ BRB-array } & \multicolumn{2}{|c|}{ SAM } & & & & & \\
\hline & $\mathrm{FDR}^{\mathrm{a}}$ & Perm- $\mathrm{p}^{\mathrm{b}}$ & Local FDR & q-value & & & & & \\
\hline \multirow[t]{2}{*}{1} & $10^{-7}$ & $10^{-7}$ & $5 \times 10^{-5}$ & 0 & TAGL & 20 & 6.55 & 22,414 & Lyon \\
\hline & & & & & & 1730 & 7.43 & 21,552 & Nantes \\
\hline 2 & $10^{-7}$ & $10^{-7}$ & $2 \times 10^{-5}$ & 0 & NNMT & 276 & 5.56 & 29,650 & Lyon \\
\hline 3 & $8 \times 10^{-5}$ & $10^{-7}$ & 0 & 0 & GUAA & 135 & 6.42 & 77,001 & Lyon \\
\hline 4 & $4 \times 10^{-6}$ & $10^{-7}$ & $1.3 \times 10^{-2}$ & 0 & FRIL & 74 & 5.55 & 19,888 & Lyon \\
\hline 5 & $5 \times 10^{-6}$ & $10^{-7}$ & 0 & 0 & ARPC3 & 1720 & 9.23 & 22,291 & Nantes \\
\hline 6 & $10^{-5}$ & $10^{-7}$ & $1.1 \times 10^{-2}$ & 0 & G3P & 1377 & 7.48 & 36,000 & Nantes \\
\hline 7 & $3 \times 10^{-5}$ & $10^{-7}$ & $6.7 \times 10^{-2}$ & 0 & PPIB & 1728 & 9.50 & 21,650 & Nantes \\
\hline 8 & $8 \times 10^{-5}$ & $2 \times 10^{-4}$ & 0 & 0 & GPDA & 168 & 5.88 & 37,439 & Lyon \\
\hline 9 & $3 \times 10^{-5}$ & $10^{-7}$ & 0 & 0 & IF5A1 & 331 & 5.10 & 17,401 & Lyon \\
\hline 10 & $2 \times 10^{-5}$ & $10^{-4}$ & 0 & 0 & FUBP1 & 101 & 7.16 & 67,560 & Lyon \\
\hline 11 & $2 \times 10^{-4}$ & $10^{-4}$ & $5.4 \times 10^{-2}$ & 0 & SNX6 & 282 & 5.81 & 46,649 & Lyon \\
\hline 12 & $2 \times 10^{-5}$ & $10^{-7}$ & $1.9 \times 10^{-2}$ & 0 & FABP4 & $812-\mathrm{C}$ & 6.80 & 14,588 & Lyon \\
\hline 13 & $10^{-7}$ & $10^{-7}$ & $5 \times 10^{-5}$ & 0 & COF1 & 1743 & 7.69 & 20,298 & Nantes \\
\hline
\end{tabular}

${ }^{a}$ FDR, false discovery rate; ${ }^{b}$ Perm-p, 10,000 permutation p-value; pI, experimental value of isoelectric point; MW, experimental value of molecular weight.

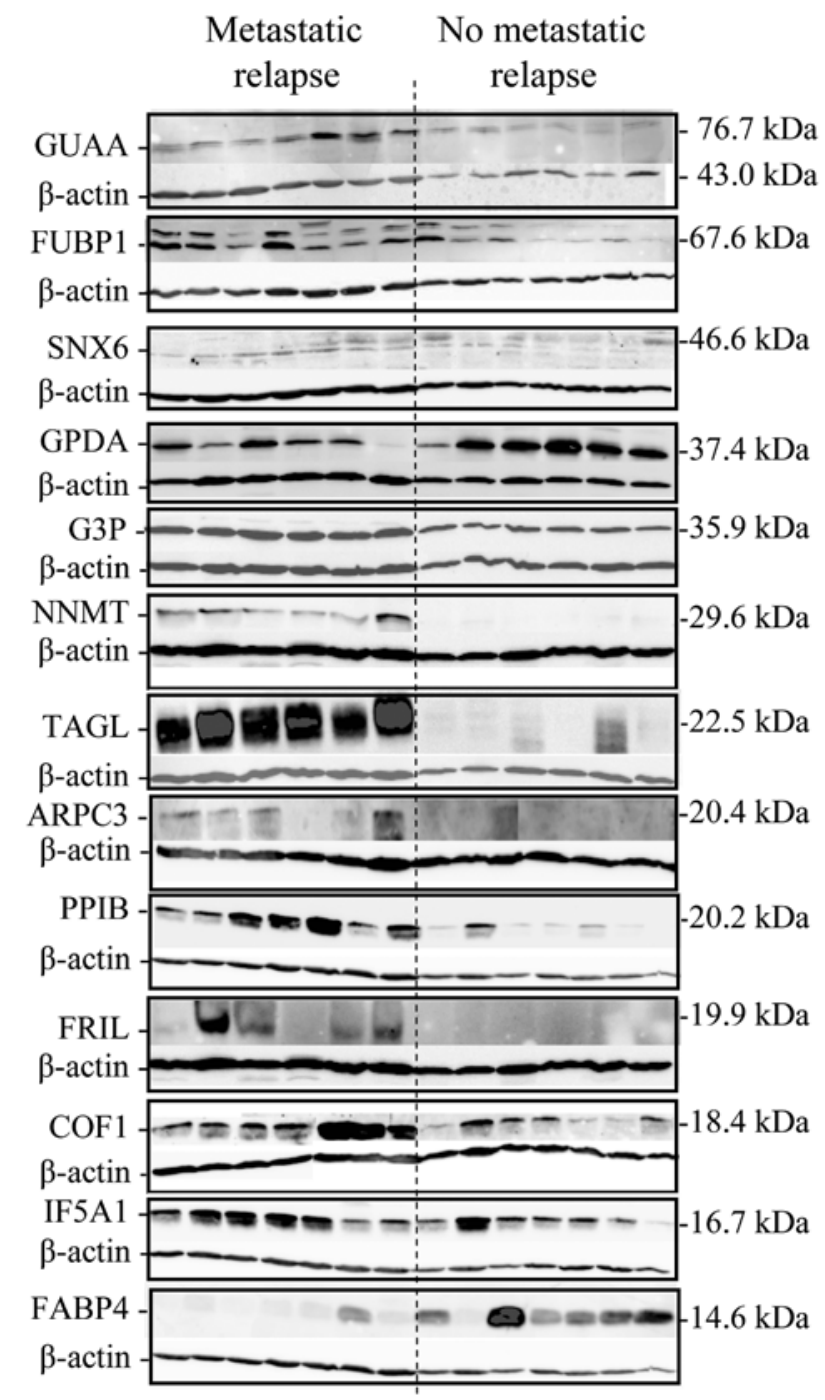

(GUAA), GAPDH (G3P), CFL1 (COF1), GPDI (GPDA). A tendency was found for SNX6, NNMT and FTL (FRIL).

Exhaustive analysis. Prognostic informativity screening in different breast cancer cohorts displayed decreasing performance from GMPS to GAPDH, CFL1, GPD1, FTL, TAGLN, $N N M T$ and SNX6. No prognostic informativity was found for ARPC3, FABP4, PPIB, FUBPI and EIF5A. Nottingham Prognostic Index (NPI)- and Adjuvant! Online (AOL)-adjusted Cox proportional hazards models showed that six markers (TAGLN, NNMT, GMPS, FTL, FUBPI and CFL1) bore independent prognostic informativity $(23,24)$; the best ones being: CFL1 (COF1), FTL (FRIL) and NNMT. Four of the five most prognostic genes [GMPS (GUAA), GAPDH(G3P), CFL1 (COF1) and FTL (FRIL)] displayed a proliferation profile (high expression in basal-like, HER $2^{+}$and luminal B molecular subtypes). These results are in concordance with numerous works showing that prognosis in breast cancer is largely dependent on proliferation status $(25,26)$. Inversely, similar to FABP4, GPD1 (GPDA) displayed a high expression in luminal A subtype and a low expression in the three other subtypes. This profile is characteristic of tumour suppressor genes. This possibility was previously evoked for FABP4 for the majority of bladder cancer (27). Gene expression correlation analyses showed a moderate correlation between TAGLN and NNMT [r(Pearson) $=0.59 ; \mathrm{p}<0.001]$, and GDPl (GPDA) and FABP4 [r(Pearson) $=0.57$; $<<0.001]$. Except for 4 selected proteins (FUBP1, SNX6, PPIB and EIF5A), which

Figure 2 . Thirteen biomarkers analyzed by western blotting in node-negative breast cancer patients with metastatic relapse (MR) or with no metastatic relapse (NR). 


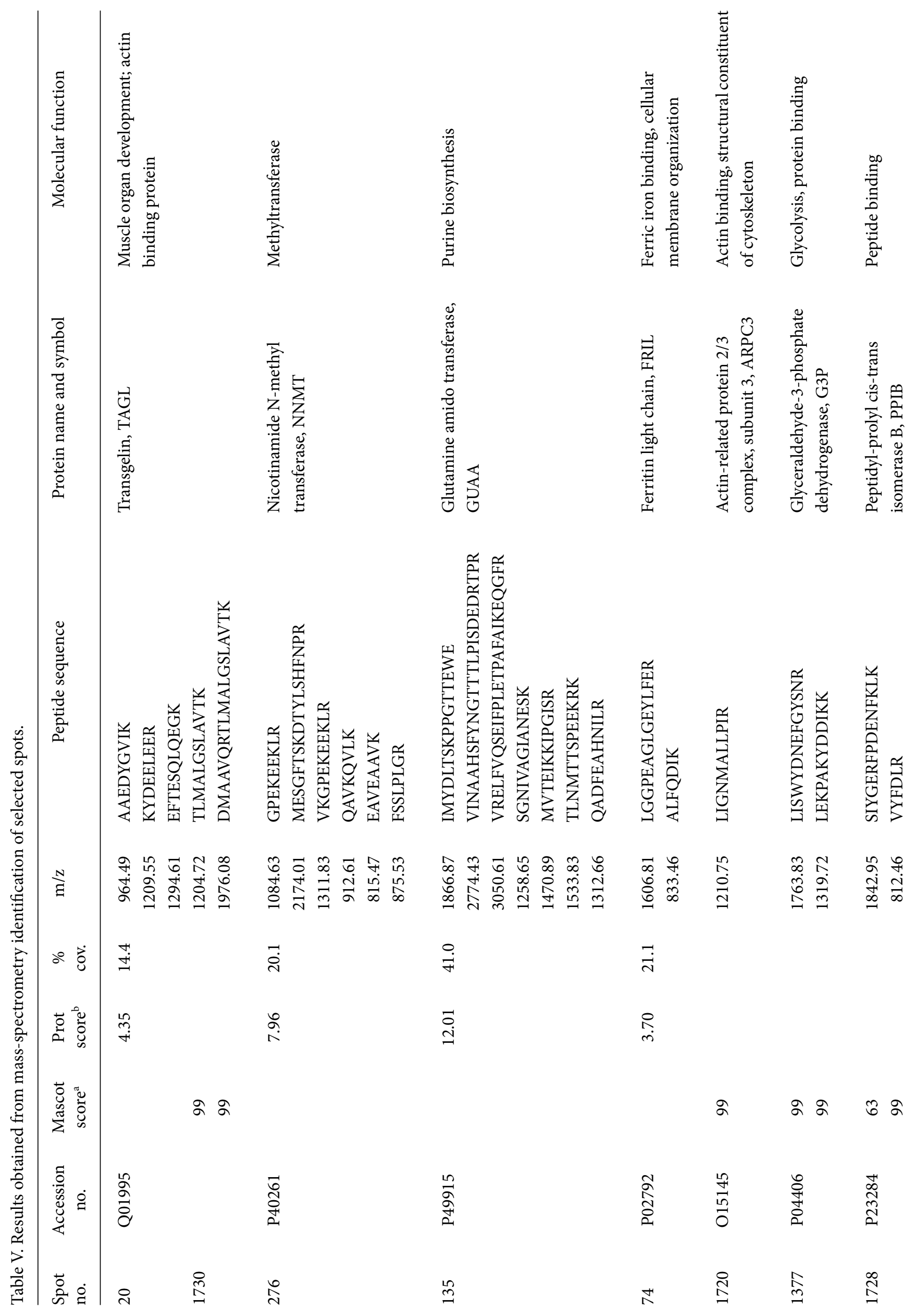




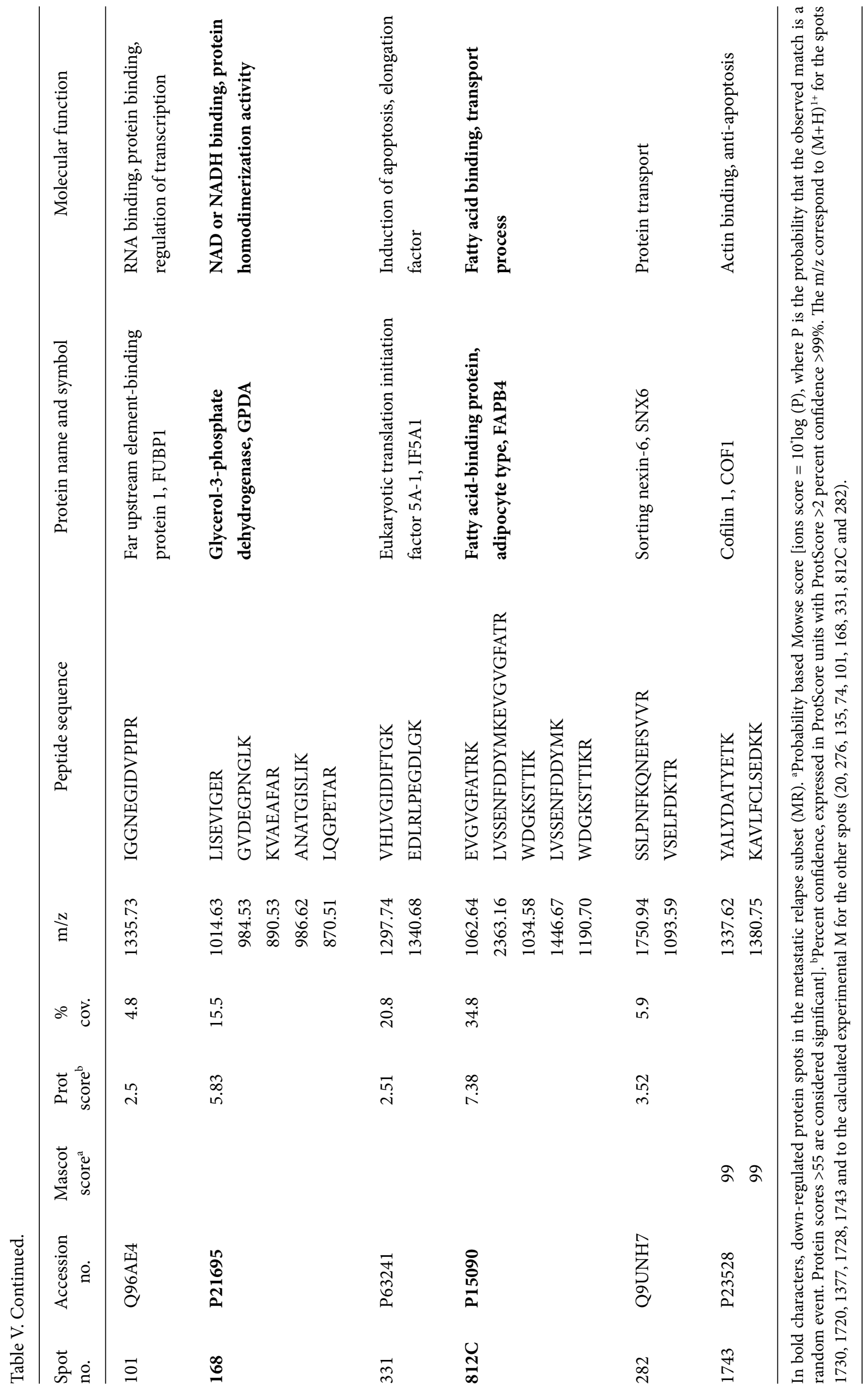


Table VI. Mann-Whitney p-values of western blot analysis.

\begin{tabular}{lr}
\hline Protein name & p-value* \\
\hline TAGL & $<0.001$ \\
NNMT & $<0.001$ \\
GUAA & 0.025 \\
FRIL & 0.015 \\
ARPC3 & 0.003 \\
G3P & 0.025 \\
PPIB & $<0.001$ \\
GPDA & 0.028 \\
IF5A1 & 0.039 \\
FUBP1 & 0.009 \\
SNX6 & 0.008 \\
FABP4 & $<0.001$ \\
COF1 & 0.021 \\
\hline
\end{tabular}

${ }^{\mathrm{a}}$ Mann-Whitney test.

displayed discordant protein/RNA expression patterns and/or low prognostic performance, all other candidates showed promising results.

\section{Discussion}

This retrospective study focused on a population of patients with ductal pNOM0 tumours: a subset of patients whose tumours have high levels of UPA and PAI-1 and who had developed metastases were compared to another subset of patients with tumours presenting low levels of UPA and PAI-1 and who did not relapse. We used a 2-DE coupled with MS approach to screen cytosol fractions using two $\mathrm{pH}$ scales, a broad scale (3.0-11.0) and a narrower scale focusing in on a protein rich region (5.0-8.0). The differential analysis of 2-DE gels allowed the identification of 13 proteins which were confirmed by western blotting. Two proteins, GPDA and FABP4 were down-regulated in the MR subset while all the others were up-regulated.

The quest for novel cancer biomarkers currently involves different '-omic' compartment screenings to increase success rate. Integrated approaches may also strengthen the selection and/or validation of molecular candidates. In this study, we chose proteomic analysis to identify prognostic markers of nodenegative breast cancer; analytical validation was performed by means of western blotting. In silico study then confirmed that 9 out of the 13 selected proteins with concordant RNA expression patterns had a significant prognostic informativity at the RNA level in independent cohorts. However, the discovery of potential new markers is far easier than their transfer into clinical practice, the latter needing their prior validation in large independent cohorts awarded only those markers displaying greater or equal strength than already validated biomarkers and clinical indexes. Markers correlated with proliferation (GUAA, G3P, COF1 and FRIL), which is the most common molecular pathway linked to breast cancer prognosis, seem to be good candidates. Recently, a clear relation has been found in mammary cell migration and breast cancer metastasis between AURKA, which is consid- ered as the prototypic marker of proliferation, and COF1. In a parallel work, the same patients were screened by means of SELDI-TOF-MS (28) and FRIL was validated as a prognostic marker. A significant correlation between FRIL values quantified by SELDI-TOF-MS and 2-DE was obtained [r(Spearman) $\left.=0.63, \mathrm{p}<10^{-4}\right]$. NPI- and AOL-adjusted analyses demonstrated that the three markers and their corresponding genes [COF1 (CFL1), NNMT (NNMT) and FRIL (FTL)] have independent prognostic informativity. For these reasons, we hypothesize that COF1 and FRIL might be the most interesting protein markers within our list.

From a basic research point of view, some of the selected markers demonstrated molecular or pathway interactions. Beyond proliferation, two other markers [FRIL (FTL) and FABP4] point out macrophages as possible effectors of breast cancer aggressiveness, as we recently underlined for FRIL (FTL) (28), FABP4 has been primarily regarded as an adipocyte- and macrophage-specific protein, however, recent studies do suggest its broader expression in endothelial cells of capillaries and small veins, the main angiogenic compartment of the vasculature. In macrophages, FABP4 participates towards the regulation of inflammatory activity and cholesterol trafficking. Its physiopathological role in cancer could be independent or synergic with macrophages. FABP4 expression is down-regulated in breast cancer cell lines in comparison with normal breast cell lines (29). In bladder transitional cell carcinoma, FABP4 protein and RNA have been found significantly decreased with increasing tumour stage and histological grade, and it has demonstrated a good prognostic value $(27,30)$.

Three of our markers (ARPC3, COF1 and TAGL) belong to the actin microfilament system, which is considered the engine behind cellular migration (31). COF1, which is activated by AURKA, interacts with TAGL and ARPC3 (Arp2/3 complex) $(32,33)$. A clear relation has been demonstrated in breast cancer between COF1 and tumour invasion and metastasis via aberrant active cell migration (33).

One bibliographical study was conducted to explain in silico the moderate correlation observed between NNMT and TAGLN genes. No link between these markers and breast cancer was underlined in the literature but three genomic studies showed significant expression of both genes in different physiological or pathological conditions. Both were overexpressed in metastatic serous papillary ovarian tumours versus primary ovarian serous carcinomas (34), in mononuclear cells of human umbilical cord blood versus its mesenchymal stem cell subpopulation (35), and in adipocytes from obese versus non-obese Pima Indians (36).

Before concluding, two points need to be raised. First, our results demonstrate that TAGLN (TAGL) is not a suppressor gene as has been previously pointed out in different cancers. We found the same pattern of expression on both 2-DE platforms, which was confirmed by western blotting, and in silico study showed that this gene was overexpressed in pejorative disease evolution. Second, GAPDH (G3P) has long been considered as a housekeeping gene and used as a reference for real-time quantitative PCR. Our results show that its protein has a prognostic value in breast cancer, and is overexpressed at the protein and RNA levels in cases of metastatic relapse. Some authors have already underlined this fact and concluded that $G A P D H$ gene should not be used as a control RNA in human breast cancer (37-39). 
In conclusion, the selection of these proteins by means of 2-DE, which permitted the differentiation of more than 2,000 protein spots per cytosolic fraction, must be considered as a preliminary exploratory study. This first phase has however led to the identification of 13 potential breast cancer biomarkers. Despite the fact that this training cohort is too small to definitively conclude on the prognostic role of these proteins, in silico analyses have shown that some of their corresponding genes have a strong prognostic impact in breast cancer, mostly because of their link with proliferation: GMPS (GUAA), GAPDH (G3P), FTL (FRIL) and GPDI (GDPA). A validation phase on a larger cohort is now needed before these biomarkers can be considered for use in clinical practice.

\section{Acknowledgements}

This study was supported by the French Ministry of Health (PHRC National 2004). English was reviewed by an independent company.

\section{References}

1. Fitzgibbons PL, Page DL, Weaver D, et al: Prognostic factors in breast cancer. College of American Pathologists Consensus Statement 1999. Arch Pathol Lab Med 124: 966-978, 2000.

2. Adjuvant therapy for breast cancer. In: NIH consensus statement, ppl-35, 2000.

3. Goldhirsch A, Glick JH, Gelber RD, Coates AS and Senn HJ: Meeting highlights: International Consensus Panel on the Treatment of Primary Breast Cancer. Seventh International Conference on Adjuvant Therapy of Primary Breast Cancer. J Clin Oncol 19: 3817-3827, 2001.

4. Goldhirsch A, Glick JH, Gelber RD and Senn HJ: Meeting highlights: International Consensus Panel on the Treatment of Primary Breast Cancer. J Natl Cancer Inst 90: 1601-1608, 1998.

5. Goldhirsch A, Wood WC, Gelber RD, Coates AS, Thurlimann B and Senn HJ: Meeting highlights: updated international expert consensus on the primary therapy of early breast cancer. J Clin Oncol 21: 3357-3365, 2003.

6. Harbeck N, Kates RE and Schmitt M: Clinical relevance of invasion factors urokinase-type plasminogen activator and plasminogen activator inhibitor type 1 for individualized therapy decisions in primary breast cancer is greatest when used in combination. J Clin Oncol 20: 1000-1007, 2002.

7. Look MP, van Putten WL, Duffy MJ, et al: Pooled analysis of prognostic impact of urokinase-type plasminogen activator and its inhibitor PAI-1 in 8377 breast cancer patients. J Natl Cancer Inst 94: 116-128, 2002.

8. Bertucci F, Houlgatte R, Benziane A, et al: Gene expression profiling of primary breast carcinomas using arrays of candidate genes. Hum Mol Genet 9: 2981-2991, 2000.

9. Bertucci F, Nasser V, Granjeaud S, et al: Gene expression profiles of poor-prognosis primary breast cancer correlate with survival. Hum Mol Genet 11: 863-872, 2002.

10. Van de Vijver MJ,He YD, van't Veer LJ, et al: A gene-expression signature as a predictor of survival in breast cancer. N Engl J Med 347: 1999-2009, 2002.

11. Van't Veer LJ, Dai H, van de Vijver MJ, et al: Gene expression profiling predicts clinical outcome of breast cancer. Nature 415: 530-536, 2002.

12. Wang Y, Klijn JG, Zhang Y, et al: Gene-expression profiles to predict distant metastasis of lymph-node-negative primary breast cancer. Lancet 365: 671-679, 2005.

13. Ricolleau G, Charbonnel C, Lode L, et al: Surface-enhanced laser desorption/ionization time of flight mass spectrometry protein profiling identifies ubiquitin and ferritin light chain as prognostic biomarkers in node-negative breast cancer tumors. Proteomics 6 : 1963-1975, 2006.

14. Bradford MM: A rapid and sensitive method for the quantitation of microgram quantities of protein utilizing the principle of proteindye binding. Anal Biochem 72: 248-254, 1976.
15. Bouchet C, Hacene K, Martin PM, et al: Dissemination risk index based on plasminogen activator system components in primary breast cancer. J Clin Oncol 17: 3048-3057, 1999.

16. Descotes F, Riche B, Saez S, et al: Plasminogen activator inhibitor type 1 is the most significant of the usual tissue prognostic factors in node-negative breast ductal adenocarcinoma independent of urokinase-type plasminogen activator. Clin Breast Cancer 8: 168-177, 2008.

17. Rabilloud T: Silver staining of 2-D electrophoresis gels. Methods Mol Biol 112: 297-305, 1999.

18. O'Connell KL and Stults JT: Identification of mouse liver proteins on two-dimensional electrophoresis gels by matrix-assisted laser desorption/ionization mass spectrometry of in situ enzymatic digests. Electrophoresis 18: 349-359, 1997.

19. Tusher VG, Tibshirani R and Chu G: Significance analysis of microarrays applied to the ionizing radiation response. Proc Natl Acad Sci USA 98: 5116-5121, 2001.

20. Gharahdaghi F, Weinberg CR, Meagher DA, Imai BS and Mische SM: Mass spectrometric identification of proteins from silver-stained polyacrylamide gel: a method for the removal of silver ions to enhance sensitivity. Electrophoresis 20: 601-605, 1999.

21. Laemmli UK: Cleavage of structural proteins during the assembly of the head of bacteriophage T4. Nature 227: 680-685, 1970.

22. Jezequel P, Campone M, Gouraud W, et al: bc-GenExMiner: an easy-to-use online platform for gene prognostic analyses in breast cancer. Breast Cancer Res Treat 131: 765-775, 2012.

23. Galea MH, Blamey RW, Elston CE and Ellis IO: The Nottingham Prognostic Index in primary breast cancer. Breast Cancer Res Treat 22: 207-219, 1992.

24. Ravdin PM, Siminoff LA, Davis GJ, et al: Computer program to assist in making decisions about adjuvant therapy for women with early breast cancer. J Clin Oncol 19: 980-991, 2001.

25. Loussouarn D, Campion L, Leclair F, et al: Validation of UBE2C protein as a prognostic marker in node-positive breast cancer. $\mathrm{Br}$ J Cancer 101: 166-173, 2009.

26. Wirapati P, Sotiriou C, Kunkel S, et al: Meta-analysis of gene expression profiles in breast cancer: toward a unified understanding of breast cancer subtyping and prognosis signatures. Breast Cancer Res 10: R65, 2008.

27. Boiteux G, Lascombe I, Roche E, et al: A-FABP, a candidate progression marker of human transitional cell carcinoma of the bladder, is differentially regulated by PPAR in urothelial cancer cells. Int J Cancer 124: 1820-1828, 2009.

28. Jezequel P, Campion L, Spyratos F, et al: Validation of tumourassociated macrophage ferritin light chain as a prognostic biomarker in node-negative breast cancer tumours: a multicentric 2004 national PHRC study. Int J Cancer (Epub ahead of print) doi: 10.1002/ijc.26397, 2011.

29. Hammamieh R, Chakraborty N, Barmada M, Das R and Jett M: Expression patterns of fatty acid binding proteins in breast cancer cells. J Exp Ther Oncol 5: 133-143, 2005.

30. Celis JE, Ostergaard M, Basse B, et al: Loss of adipocyte-type fatty acid binding protein and other protein biomarkers is associated with progression of human bladder transitional cell carcinomas. Cancer Res 56: 4782-4790, 1996.

31. Lambrechts A, van Troys M and Ampe C: The actin cytoskeleton in normal and pathological cell motility. Int J Biochem Cell Biol 36: 1890-1909, 2004.

32. DesMarais V, Macaluso F, Condeelis J and Bailly M: Synergistic interaction between the Arp2/3 complex and cofilin drives stimulated lamellipod extension. J Cell Sci 117: 3499-3510, 2004.

33. Wang LH, Xiang J, Yan M, et al: The mitotic kinase Aurora-A induces mammary cell migration and breast cancer metastasis by activating the Cofilin-F-actin pathway. Cancer Res 70: 9118-9128, 2005.

34. Bignotti E, Tassi RA, Calza S, et al: Gene expression profile of ovarian serous papillary carcinomas: identification of metastasisassociated genes. Am J Obstet Gynecol 196: 245 e241-211, 2007.

35. Jeong JA, Hong SH, Gang EJ, et al: Differential gene expression profiling of human umbilical cord blood-derived mesenchymal stem cells by DNA microarray. Stem Cells 23: 584-593, 2005.

36. Lee YH, Nair S, Rousseau E, et al: Microarray profiling of isolated abdominal subcutaneous adipocytes from obese vs non-obese Pima Indians: increased expression of inflammation-related genes. Diabetologia 48: 1776-1783, 2005.

37. Lu H, Zhang Y, Roberts DD, Osborne CK and Templeton NS: Enhanced gene expression in breast cancer cells in vitro and tumors in vivo. Mol Ther 6: 783-792, 2002. 
38. Revillion F,Pawlowski V, Hornez L and Peyrat JP: Glyceraldehyde3 -phosphate dehydrogenase gene expression in human breast cancer. Eur J Cancer 36: 1038-1042, 2000.

39. Valenti MT BF, Dalle Carbonare L, Azzarello G, Zenari S, Zanatta M, Balducci E, Vinante O and Lo Cascio V: The effect of bisphosphonates on gene expression: GAPDH as a housekeeping or a new target gene? BMC Cancer 6: 49, 2006.

40. Sotiriou C, Neo SY, McShane LM, et al: Breast cancer classification and prognosis based on gene expression profiles from a populationbased study. Proc Natl Acad Sci USA 100: 10393-10398, 2003.

41. Ma XJ, Wang Z, Ryan PD, et al: A two-gene expression ratio predicts clinical outcome in breast cancer patients treated with tamoxifen. Cancer Cell 5: 607-616, 2004.

42. Minn AJ, Gupta GP, Siegel PM, et al: Genes that mediate breast cancer metastasis to lung. Nature 436: 518-524, 2005.

43. Pawitan Y, Bjöhle J, Amler L, et al: Gene expression profiling spares early breast cancer patients from adjuvant therapy: derived and validated in two population-based cohorts. Breast Cancer Res 7: R953-R964, 2005.

44. Weigelt B, Hu Z, He X, et al: Molecular portraits and 70-gene prognosis signature are preserved throughout the metastatic process of breast cancer. Cancer Res 65: 9155-9158, 2005.

45. Bild AH, Yao G, Chang JT, et al: Oncogenic pathway signatures in human cancers as a guide to targeted therapies. Nature 439 353-357, 2006.

46. Chin K, DeVries S, Fridlyand J, et al: Genomic and transcriptional aberrations linked to breast cancer pathophysiologies. Cancer Cell 10: 529-541, 2006.

47. Ivshina AV, George J, Senko O, et al: Genetic reclassification of histologic grade delineates new clinical subtypes of breast cancer. Cancer Res 66: 10292-10301, 2006.

48. Desmedt C, Piette F, Loi S, et al: Strong time dependence of the 76-gene prognostic signature for node-negative breast cancer patients in the TRANSBIG multicenter independent validation series. Clin Cancer Res 13: 3207-3214, 2007.
49. Loi S, Haibe-Kains B, Desmedt C, et al: Definition of clinically distinct molecular subtypes in estrogen receptor-positive breast carcinomas through genomic grade. J Clin Oncol 25: 1239-1246, 2007.

50. Minn AJ, Gupta GP, Padua D, et al: Lung metastasis genes couple breast tumor size and metastatic spread. Proc Natl Acad Sci USA 104: 6740-6745, 2007.

51. Naderi A, Teschendorff AE, Barbosa-Morais NL, et al: A geneexpression signature to predict survival in breast cancer across independent data sets. Oncogene 26: 1507-1516, 2007.

52. Anders CK, Acharya CR, Hsu DS, et al: Age-specific differences in oncogenic pathway deregulation seen in human breast tumors. PLoS One 3: e1373, 2008.

53. Chanrion M, Negre V, Fontaine $\mathrm{H}$, et al: A gene expression signature that can predict the recurrence of tamoxifen-treated primary breast cancer. Clin Cancer Res 14: 1744-1752, 2008.

54. Loi S, Haibe-Kains B, Desmedt C, et al: Predicting prognosis using molecular profiling in estrogen receptor-positive breast cancer treated with tamoxifen. BMC Genomic 9: 239, 2008.

55. Schmidt M, Böhm D, von Törne C, et al: The humoral immune system has a key prognostic impact in node-negative breast cancer. Cancer Res 68: 5405-5413, 2008.

56. Calabrò A, Beissbarth T, Kuner R, et al: Effects of infiltrating lymphocytes and estrogen receptor on gene expression and prognosis in breast cancer. Breast Cancer Res Treat 116: 69-77, 2009.

57. Jézéquel P, Campone M, Roché $\mathrm{H}$, et al: A 38-gene expression signature to predict metastasis risk in node-positive breast cancer after systemic adjuvant chemotherapy: a genomic substudy of PACS01 clinical trial. Breast Cancer Res Treat 116: 509-520, 2009.

58. Zhang Y, Sieuwerts AM, McGreevy M, et al: The 76-gene signature defines high-risk patients that benefit from adjuvant tamoxifen therapy. Breast Cancer Res Treat 116: 303-309, 2009. 